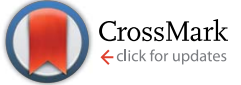

Cite this: J. Mater. Chem. A, 2016, 4, 11397

Received 10th May 2016

Accepted 29th June 2016

DOI: $10.1039 / c 6 t a 03903 k$

www.rsc.org/MaterialsA

\section{The goldilocks electrolyte: examining the performance of iron/nickel oxide thin films as catalysts for electrochemical water splitting in various aqueous $\mathrm{NaOH}$ solutions $\uparrow$}

\author{
Michelle P. Browne,* Shelley Stafford, Maria O'Brien, Hugo Nolan, Nina C. Berner, \\ Georg S. Duesberg, Paula E. Colavita and Michael E. G. Lyons*
}

A rigorous study of electrodeposited pure and mixed Ni/Fe oxides was performed in three different sodium hydroxide electrolytes with various Fe impurity concentrations ( $<1$ ppb, 5 ppb and 102 ppb). The presence and concentration of the Fe impurities in the three electrolytes is determined by Inductive Coupled Plasma spectroscopy. The rationale for investigating the OER performance of the pure and mixed $\mathrm{Ni} / \mathrm{Fe}$ catalysts in various $\mathrm{NaOH}$ solutions, rather than the widely reported and more expensive $\mathrm{KOH}$, with different Fe impurities was to conclude if the OER activity was comparable to the $\mathrm{KOH}$ and if the activity differed between $\mathrm{NaOH}$ solutions. A number of the mixed $\mathrm{Ni} /$ Fe catalysts in $\mathrm{NaOH}$ containing Fe impurities at a concentration of $5 \mathrm{ppb}$ exhibited higher OER activities, with higher Turnover Frequency than the same catalyst in the $\mathrm{NaOH}$ solutions containing $<1 \mathrm{ppb}$ and $102 \mathrm{ppb}$ and the state if the art $\mathrm{RuO}_{2}$. These $\mathrm{Ni} / \mathrm{Fe}$ oxide materials are also cheaper to produce than the aforementioned platinum group materials therefore rendering these $\mathrm{Ni} / \mathrm{Fe}$ catalysts more practical and economical. All of the material/electrolyte combinations are also evaluated with respect to their Tafel slopes and measured overpotential at a current density of $10 \mathrm{~mA} \mathrm{~cm}{ }^{-2}$. To determine the $\mathrm{Ni}$ and Fe species formed before and after OER ex-situ Raman spectroscopy and X-ray photoelectron spectroscopy are utilised. Interestingly, the oxidation state of the Ni species in the pure Ni material does not change during OER in any of the $\mathrm{NaOH}$ media. While for the pure Fe and mixed Ni/Fe 50/50 material, the oxidation states of the species vary with the concentration of Fe impurities in the $\mathrm{NaOH}$ solution.

\section{Introduction}

Alkaline water electrolysis has been proposed as an environmentally inoffensive route to the production of the large volumes of pure hydrogen gas. ${ }^{1}$ The $\mathrm{H}_{2}$ gas produced by this route can be used in a $\mathrm{H}_{2} / \mathrm{O}_{2}$ fuel cell to create electrical energy for a national grid or electric cars. A number of renewable sources can be coupled with water electrolysers to produce the driving force behind this technology e.g. photovoltaics or wind turbines. This forms the basis of the so-called hydrogen economy. Alternatively, photoelectrochemical cells (PEC) using semiconductor materials as the anode provides another route to produce pure $\mathrm{H}_{2}$ fuel. ${ }^{2,3}$ In the PEC when a photon of energy higher than the semi-conductor's band gap, is absorbed by the anode material, an electron-hole pair is created. ${ }^{4}$ The electron-hole pair is separated by the electric field at the

School of Chemistry \& CRANN, Trinity College, Dublin 2, Ireland. E-mail: brownem6@ tcd.ie; melyons@tcd.ie

$\dagger$ Electronic supplementary information (ESI) available. See DOI: $10.1039 / \mathrm{c} 6 \mathrm{ta} 03903 \mathrm{k}$ interface between the anode and the electrolyte. The water molecules are oxidised at the anode interface by the holes to produce $\mathrm{O}_{2}$ and the electrons travels to the cathode to participate in the Hydrogen Evolution Reaction (HER) for the generation of $\mathrm{H}_{2}{ }^{2}$. Typically a metal oxide catalyst is deposited on the semiconducting anode to facilitate the oxidation of water. Hence the functions of photon harvesting and catalysis are separated to ensure optimum efficiency.

Regardless of the route taken to generate the $\mathrm{H}_{2}$, the efficiency of water electrolysis is limited by the large anodic overpotential of the Oxygen Evolution Reaction (OER) on the anode. ${ }^{5}$ OER is also a crucial half reaction for many other reactions including rechargeable metal air batteries. ${ }^{6}$ Currently, the optimal OER metal oxide anode materials in alkaline media include the platinum group metals; ruthenium and iridium oxides as these oxides exhibit the lowest overpotentials for the OER at practical current densities. ${ }^{7,8}$ However, the high cost of these materials compared to other metals and their lack of abundance renders their widespread commercial utilisation uneconomical. ${ }^{5}$ For these reasons, the oxides of the first row transition metals (e.g. manganese, iron, cobalt and nickel) offer 
a compromise solution to the critical platinum group metals. ${ }^{9-20}$

Recent work has revealed that $\mathrm{Ni}_{1-x} \mathrm{Fe}_{x} \mathrm{OOH}$ electrode materials function as effective water oxidation catalysts in alkaline media, ${ }^{21-24}$ These mixed oxy-hydroxide thin films, formed via electrochemical deposition, have been shown to generate oxygen at a rate of $10 \mathrm{~mA} \mathrm{~cm} \mathrm{~cm}^{-2}$ at very low overpotentials. The relevance of the overpotential value observed corresponding to a fixed current density of $10 \mathrm{~mA} \mathrm{~cm}{ }^{-2}$ in the active oxygen evolution region has been articulated by Jaramillo. $^{25}$ The rationale for quoting the latter rather arbitrary numerical metric as a performance indicator for efficient electrocatalysis can be explained as follows. The overpotential value at $10 \mathrm{~mA} \mathrm{~cm}{ }^{-2}$ (which we represent at $\eta_{10}$ ) recorded for a particular water oxidation catalyst is that what would be expected for a generic solar-to-fuel device operating at $10 \%$ efficiency under AM 1.5G illumination (equal to $100 \mathrm{~mW} \mathrm{~cm}^{-2}$ ). Power $(P)$ is given by the product of current by potential so: $P=E I, I=P / E$. Additionally, the HER and OER are separated by a potential window of approximately $1.23 \mathrm{~V}$, therefore the current density at which water splitting would take place in a $100 \%$ efficient solar-to-fuel device is $81.3 \mathrm{~mA} \mathrm{~cm}^{-2} .^{25}$ Therefore a solar-to-fuel device operating at $10 \%$ efficiency would typically draw $8.13 \mathrm{~mA} \mathrm{~cm}{ }^{-2}$, which is usually rounded up to $10 \mathrm{~mA} \mathrm{~cm}^{-2}$ for convenience.

The incorporation of Fe impurities into Ni oxide to improve its OER activity was first observed by Corrigan et al. in the 1980 's. ${ }^{26}$ These workers reported that the addition of just 1 ppm of iron into a nickel oxide film resulted in the decrease in the OER overpotential compared to that of observed for pure nickel oxide. Corrigan also noted that the overpotential further decreased with further Fe incorporation into the Ni oxide film. ${ }^{26}$ However, this important result remained largely unnoticed, and it is only in recent years that the role of intentional and incidental iron incorporation into nickel oxy-hydroxide thin films in contact with aqueous $\mathrm{KOH}$ solutions has been systematically examined. ${ }^{1522-24}$ We note that pure nickel oxide thin film materials exhibit $\eta_{10}$ values lying between 500 and $700 \mathrm{mV}$ depending on the purity of the base used, while the corresponding $\eta_{10}$ reported for iron oxides is approximately $550 \mathrm{mV}^{23,26,27}$ Hence, recent work has confirmed that the addition of small quantities of Fe into nickel oxy-hydroxide films can significantly enhance the OER catalytic activity of the latter, although the mechanism by which this catalytic enhancement occurs is still not totally established.

Trotochaud et al. performed electrochemical, in situ electrical, XPS and XRD measurements on $\mathrm{Ni}_{1-x} \mathrm{Fe}_{x}(\mathrm{OH})_{2} / \mathrm{Ni}_{1-x} \mathrm{Fe}_{x} \mathrm{OOH}$ thin films in aqueous $\mathrm{KOH}$ solutions. ${ }^{22}$ In this work the $\mathrm{KOH}$ solutions were of two types: (i) those purified and free of trace Fe impurities and (ii) those not subjected to the purification procedure containing ppb levels of Fe. This work sought to examine the effect that Fe inclusion has on the electronic conductivity, structure and OER catalytic behaviour of mixed $\mathrm{Ni} / \mathrm{Fe}$ oxyhydroxide thin films. Cyclic voltammetry performed on $\mathrm{Ni}(\mathrm{OH})_{2} / \mathrm{NiOOH}$ thin films in contact with purified $\mathrm{Fe}$ free $\mathrm{KOH}$ solutions indicated the absence of significant OER activity until a potential greater that $0.4 \mathrm{~V} v$ s. $\mathrm{Hg} / \mathrm{HgO}$ was applied. These workers also suggested that the
$\beta$-NIOOH phase is less active for OER than the disordered $\gamma-\mathrm{NiOOH}$ starting material and that previous reports indicating that $\beta$-NiOOH exhibits enhanced OER activity brought about by ageing and crystallization is possibly mistaken. The suggestion is that the observed activity rise can be attributed to Fe impurity incorporation into the $\mathrm{NiOOH}$ lattice during the ageing process. Hence it is quite possible that the current wisdom suggesting that $\beta$-NiOOH is the 'right type of oxide' for OER is mistaken. Interestingly Trotochaud et $a .^{22}$ used a pair of IDA electrodes to measure the conductivity of the oxide catalyst film which was deposited across the neighbouring microbands, over the potential range $0.3-0.6 \mathrm{~V}$ vs. $\mathrm{Hg} / \mathrm{HgO}$. This enabled the potential corresponding to the onset of conductivity turn-on to be identified as a function of Fe content in the thin film. A sharp increase in conductivity was observed at the potential corresponding to the $\mathrm{Ni}^{2+} / \mathrm{Ni}^{3+}$ redox transition. Furthermore the conductivity turn-on shifts to higher potentials with increasing Fe content again mirroring the behaviour of the $\mathrm{Ni}^{2+} / \mathrm{Ni}^{3+}$ voltammetric peak. Hence one concludes that incorporation of $\mathrm{Fe}$ increases the electronic conductivity of the NiOOH film. Trotochaud et al. noted a difference of $200 \mathrm{mV}$ in the $\eta_{10}$ value for oxygen evolution when $\mathrm{NiOOH}$ and $\mathrm{Ni}_{0.75} \mathrm{Fe}_{0.25} \mathrm{OOH}$ thin films (ca. $40 \mathrm{~nm}$ thickness) were compared. ${ }^{22}$ Trotochaud et al. determined the conductivity of the $\mathrm{Ni}$ oxide film to be only of one order of magnitude less than the films with 5-25\% Fe precursor content. ${ }^{22}$ This OER activity difference could not be fully accounted for in terms of conductivity differences between the films.

Bell et al. utilised electrochemical Impedance spectroscopy (EIS) which found that the pure Ni and Fe oxides exhibited high faradic resistance compared to the mixed materials. ${ }^{16}$ Bell et al. quoted resistance values at an overpotential of $350 \mathrm{mV}$ of $273 \Omega$ for the electrodeposited $\mathrm{FeOOH}$, which is a much smaller value quoted by Doyle et al. for hydrous Fe. ${ }^{1628}$ However, again, regardless of the fabrication method and the resistance values of the Fe material, the electrodeposited and hydrous Fe exhibit similar OER activity. ${ }^{16,28,29}$ Furthermore, Bell et al. reported the material with the highest capacitance value was the $75 \% \mathrm{Fe}$ sample, however this catalyst is notably less active then the mixed catalysts containing $50 \%$ Fe or less. ${ }^{16}$ As of yet, it is still unclear as to the underpinning phenomenon for the observed catalytic synergy between the $\mathrm{Ni}$ and Fe oxide materials.

Friebel et al. used Density-Functional Theory (DFT) calculations to determine that electrodeposited mixed Ni/Fe oxides are produced in two phases depending on the initial precursor Fe concentration present in the deposition solution. For low amounts of Fe precursor the $\gamma$-NiOOH:Fe phase is present, while the phase formed at high amounts of Fe precursor is $\gamma$-FeOOH with little or no Ni oxide. ${ }^{27}$ In operando X-ray absorption spectroscopy has also been used to determine that the active site of the mixed $\mathrm{Ni} / \mathrm{Fe}$ oxide is the $\mathrm{Fe}^{3+} \cdot{ }^{27}$ This site is believed to substitute in the Ni oxide lattice for Ni atoms, not between the $\mathrm{Ni}$ layers. The $\mathrm{Fe}^{3+}$ occupies one of the $\mathrm{NiO}_{6}$ octahedrally structured crystals, while the $\mathrm{Fe}-\mathrm{O}$ bond is decreased compared to the original Ni-O bond..$^{27}$ The oxidation state of the $\mathrm{Ni}$ oxide in this material increases from $\mathrm{Ni}^{2+}$ to $\mathrm{Ni}^{4+}$ during OER. Therefore the mixed $\mathrm{Ni} / \mathrm{Fe}$ oxide species present during OER in terms of oxidation states can be written as $\mathrm{Ni}^{4+} \mathrm{Fe}^{3+}$ or 
$\mathrm{NiFe}_{2} \mathrm{O}_{4} \mathrm{OH}$. However, Landon recently reported, using in situ EXAFS, that the Ni K-edge of a Ni 90/Fe 10 oxide catalyst that did not change during oxygen evolution conditions, indicating that the $\mathrm{Ni}^{2+}$ species was still present in materials with $\mathrm{Fe}^{30}$ Additionally, Goerlin et al., also using EXAFS, has recently shown that in Fe-free $\mathrm{KOH}$ a Ni/Fe oxide catalyst with a Fe concentration of $4 \%$ has its $\mathrm{Ni}$ oxide in a partial oxidation state of $2+$ under OER conditions. ${ }^{31}$ While, interestingly, the $\mathrm{Ni}$ atoms in a 91 : $9 \mathrm{Ni} / \mathrm{Fe}$ oxide fully remain in a $2+$ oxidation state during OER. $^{31}$

In this work, electrodeposited $\mathrm{Ni} / \mathrm{Fe}$ oxide materials are electrochemically fabricated on Ti supports, in order to investigate their potential as an OER catalyst in alkaline solutions. In particular, different amounts of $\mathrm{Fe}$ impurities at a controlled level ( $<1$ ppb, 5 ppb and $102 \mathrm{ppb}$ ) in the electrolyte are used to examine the OER activity of each $\mathrm{Ni} / \mathrm{Fe}$ oxide catalysts. To the authors' knowledge, the effect on the OER activity of various levels of $\mathrm{Fe}$ impurity in $\mathrm{NaOH}$ has not been investigated before. Previous studies have only dealt with the presence of Fe impurities versus none, rather than the influence of varying concentrations of Fe impurity. The concentration of the Fe impurities in the electrolytes in this study was determined by Inductive Coupled Plasma (ICP) spectroscopy. The results indicate that the electrocatalytic activity of the materials depends on the ratio of $\mathrm{Ni} / \mathrm{Fe}$ and the concentration of Fe impurities in the electrolyte. Most of the mixed catalysts show improved OER performances compared to the pure $\mathrm{Ni}$ and Fe oxide materials with respect to various Key Performance Indicators (KPI's), which include overpotential at $10 \mathrm{~mA} \mathrm{~cm} \mathrm{~cm}^{-2}$, Tafel slope values and Turnover Frequencies (TOF) numbers. The composition, morphology and structure of these materials before and after OER are thoroughly characterised by X-ray Photoelectron Spectroscopy (XPS), Scanning Electron Microscopy-Energy Dispersive X-ray (SEM-EDX) and Raman spectroscopy. High Resolution XPS of the relevant core levels is further utilised to determine the oxidation of the Ni/Fe oxide materials after OER in all electrolytes used in this study. The XPS interestingly reveals that the $\mathrm{Ni} 100$ catalyst remained in its $\mathrm{Ni}^{2+}$ state during OER.

\section{Experimental}

\section{Materials}

The materials and reagents used in these experiments were sulfuric acid (Sigma Aldrich, 95-97\%, analytical grade), alumina powder (Sigma Aldrich), 1200 grit carbimet paper (Buehler), nickel(II) sulfate heptahydrate (Sigma Aldrich, $\geq 99 \%$ metal basis, M. $280.86 \mathrm{~g} \mathrm{~mol}^{-1}$ ), iron(II) sulfate heptahydrate (Sigma Aldrich, $\geq 99 \%$ metal basis, M. $278.01 \mathrm{~g} \mathrm{~mol}^{-1}$ ), butanol (Sigma Aldrich, $\geq 99 \%$, reagent-grade), mercury-mercuric oxide $(\mathrm{Hg} / \mathrm{HgO})$ reference electrode ( $\mathrm{CH}$ instruments, cat no. 152), sodium hydroxide pellets (Sigma-Aldrich, $\geq 98 \%$, reagentgrade), sodium hydroxide pellets (VWR, RECTAPUR grade $\geq$ 99\%), carbon tabs (Agar Scientific), copper tape (Agar Scientific). The $\mathrm{Ni} / \mathrm{Fe}$ oxide materials were deposited on a layer of $\mathrm{SiO}_{2}$ $(300 \mathrm{~nm})$ on top of Si wafers (SiMat), subsequently coated with Ti (see below).

\section{Electrode fabrication}

Electron beam evaporation was carried out in a Temescal FC-2000 to deposit titanium to thicknesses of $150 \mathrm{~nm}$ on $\mathrm{Si} / \mathrm{SiO}_{2}$ wafers. Subsequently, the $\mathrm{Ti} / \mathrm{SiO}_{2} / \mathrm{Si}$ wafers were immersed in an electrodepositing solution with a concentration of $6 \mathrm{mM}$ of a mixture of the relevant salts. Seven depositing solutions were made with a Fe content of $0,10,25,50,75,90$ and 100\%, with the remainder consisting of $\mathrm{Ni}$ depositing solution in each case. For example, the fabrication of the Fe 50 film used $3 \mathrm{mM}$ of the nickel(II) sulfate heptahydrate and $3 \mathrm{mM}$ of the iron(II) sulfate heptahydrate diluted in deionised water in a $100 \mathrm{ml}$ volumetric flask. The $\mathrm{pH}$ of the solutions was not adjusted. All solutions were degassed for 15 minutes before deposition. Films were galvanostatically deposited for 1100 seconds at a current density of $50 \mu \mathrm{A}$ with a graphite rod as the counter electrode and an $\mathrm{Ag} / \mathrm{AgCl}$ as the reference electrode.

\section{$\mathrm{NaOH}$ electrolyte Fe concentrations and purification}

Three different $\mathrm{NaOH}$ solutions with varying amounts of Fe impurity were used in this study to evaluate the OER activity of the pure and mixed Ni/Fe oxides. Two $\mathrm{NaOH}$ solutions were used as-purchased from VWR (RECTAPUR grade $\geq 99 \%$ ) and Sigma Aldrich Sigma-Aldrich ( $\geq 98 \%$, reagent-grade). ICP spectroscopy revealed the Fe concentrations were $102 \mathrm{ppb}$ and 5 ppb, respectively; Fig. S1 and Table S2. $\dagger$ Further purification of the $\mathrm{NaOH}$ solution, purchased from VWR, resulted in the concentration of Fe to be $<1$ ppb, Fig. S1 and Table S2. $\dagger$ The purification technique used is adapted from a $\mathrm{KOH}$ purification procedure by previous authors. ${ }^{15,22}$ Full details in ESI. $\dagger$

\section{Characterisation}

The materials fabricated were characterised by various analytical techniques. The morphology of the electrocatalysts on the titanium wire were determined using a Karl Zeiss Ultra Field Emission SEM at an accelerating voltage between 2 and $15 \mathrm{kV}$ at a working distance between 1 and $5 \mathrm{~mm}$; elemental analysis was carried out using an EDX detector from Oxford Instruments. All Raman spectroscopy measurements were performed using a Witec alpha 300R confocal Raman microscope using a 600 line $\mathrm{mm}^{-1}$ grating and a $532 \mathrm{~nm}$ diode laser at an incident power of $<10 \mathrm{~mW}$ and a spot size of $300 \mathrm{~nm}$. XPS measurements were carried out using a VG Scientific ESCALab MKII system using an Al $K_{\alpha}$ X-ray source $(1486.7 \mathrm{eV})$. The sample spot size was approximately $2 \mathrm{~mm}$, meaning a large area of the sample was analysed and spectra are indicative of the whole sample rather than discrete locations. For survey scans, an analyser pass energy of $200 \mathrm{eV}$ was used while a pass energy of $20 \mathrm{eV}$ was used to obtain high resolution spectra of characteristic core levels. The binding energy scale was referenced to the $\mathrm{C} 1 \mathrm{~s}$ peak of adventitious carbon at $284.8 \mathrm{eV}$ and the high resolution core level peaks were subsequently fitted using the Casa XPS software.

\section{Electrochemical measurements}

All electrochemical experiments were undertaken in a standard three-electrode cell using a high performance 
digital potentiostat $(\mathrm{CH}$ model $1760 \mathrm{D} \mathrm{Bi}$-potentiostat system monitored using $\mathrm{CH} 1760 \mathrm{D}$ electrochemical workstation beta software). The working electrodes consisted of the titanium film substrate with an electrodeposited Ni/Fe film, as described in the section above. A graphite rod was employed as a counter-electrode and a mercury-mercuric oxide $(\mathrm{Hg} / \mathrm{HgO})$ reference electrode was used as a reference standard. The various electrolyte solutions used for the electrochemical behaviour studies of the different electrocatalysts produced, including polarisation and Tafel analysis, were prepared from $\mathrm{NaOH}$ pellets. Electrochemical measurements were taken at a constant temperature of $25{ }^{\circ} \mathrm{C}$, using a thermal bath with the temperature maintained by a thermostat. All solutions were degassed with $\mathrm{N}_{2}$ for 15 minutes before commencing any analysis, to eliminate any dissolved oxygen present in the electrolyte. Cyclic voltammetry (CV) experiments were conducted in aqueous $1.0 \mathrm{M} \mathrm{NaOH}$ at $40 \mathrm{mV} \mathrm{s}^{-1}$ between the limits of $-0.6 \mathrm{~V}$ and $+0.8 \mathrm{~V} v s$. $\mathrm{Hg} / \mathrm{HgO}$. Polarisation and Tafel plot measurements were performed at a sweep rate of $1 \mathrm{mV} \mathrm{s}^{-1}$ in the forward oxidation direction. The uncompensated solution resistance was usually determined at a 90\% compensation level. All plotted data are presented in iR compensated form; the iR compensation was calculated from a built-in iR compensation module in the $\mathrm{CH}$ - instrument software. The voltammetric charge $(Q)$ obtained for use in the normalisation of the polarisation, Tafel plots and for the calculation of the TOF was determined by integrating the area under the oxidation sweep of the relevant voltammogram in $1 \mathrm{M} \mathrm{NaOH}$. It is assumed the redox active sites for a material are the same active sites involved in OER. The TOF was calculated at an overpotential of $0.35 \mathrm{~V}$ as TOF $=J_{E} / 4 Q$, where $J_{E}$ is the current density at the potential $E, Q$ is the charge associated with the redox processes occurring on the electrode and the multiplication factor 4 is used, as the OER is a four electron transfer reaction. Stability tests were performed on relevant materials in $1 \mathrm{M} \mathrm{NaOH}$ by applying a potential of $0.7 \mathrm{~V} v s$. $\mathrm{Hg} / \mathrm{HgO}$ for a period of time.

\section{Results and discussion}

\section{Physical characterisation}

The role of Fe in potassium hydroxide $(\mathrm{KOH})$ is well investigated throughout the literature for pure and mixed $\mathrm{Ni} / \mathrm{Fe}$ oxides as OER electrocatalysts. ${ }^{12,15,16,21,22,24,29,32,33}$ However, to the best of the authors' knowledge, no study has been conducted on the role of $\mathrm{NaOH}$ and the implications of different Fe concentrations in the electrolyte for these pure and mixed oxides, to date. Previous studies by Gao et al. for Mn oxides reveals that the electrolyte used e.g. $\mathrm{KOH}, \mathrm{NaOH}, \mathrm{CsOH}$ or $\mathrm{LiOH}$, will affect the OER mechanism and hence the current densities at which the OER will occur. ${ }^{34}$ This study correlates the increase in current with the increase in atomic radii of the alkali-metal in the electrolyte. Gao et al. discovered for the same starting Mn oxide material, different Mn oxidation states were observed during the OER regime in the aforementioned electrolytes. This study shows that the electrolyte used is also extremely important when investigating OER catalysts. Our study using $\mathrm{NaOH}$ is important to understanding the overall roles of $\mathrm{Ni} / \mathrm{Fe}$ oxide OER catalysts. Subsequently, the Ni/Fe pure and mixed electrodes, prepared in this study, will be investigated in $3 \mathrm{NaOH}$ electrolytes each containing different amounts of $\mathrm{Fe}(<1 \mathrm{ppb}, 5 \mathrm{ppb}$ and $102 \mathrm{ppb})$. This will investigate if there is an optimum amount of Fe needed in the $\mathrm{NaOH}$ electrolyte.

A full electrochemical study on the pure and mixed Ni/Fe oxides, including cyclic voltammetry, Tafel plots, Linear Sweep Voltammetry (LSV) (normalised to geometric area), and the calculation of the Turnover frequencies (TOF) numbers, have been untaken in all three $\mathrm{NaOH}$ electrolytes, previously described in the Experimental section, to help determine the optimum concentration of Fe in the electrolyte to help facilitate in the OER. All seven Ni/Fe oxide catalysts will undergo these experiments to determine the optimum Ni/Fe oxide for the OER in each electrolyte. From this point, the Ni/Fe oxide catalysts will be referred to by the amount of Fe present in the electrodepositing/precursor solution i.e. Fe 75 will describe an electrode fabricated from an electrodepositing solution which is made from $75 \%$ iron sulfate and $25 \%$ nickel sulfate; see Table $\mathrm{S} 1$ in the ESI $\uparrow$ for a full list of all materials.

SEM was employed to determine the morphology of all the as-deposited catalysts. The Fe 0 shows a particle morphology while the pure Fe 100 shows a similar morphology but with a rough-like surface. Interestingly, the Fe 25, 50 and 75 exhibit a mesh structure, which could increase the surface area of the catalyst and help in the facilitation of the OER. Interestingly, for the Fe 50, the morphology of the film differs slightly after OER depending on the Fe impurities concentration in the $\mathrm{NaOH}$, Fig. S4. $\uparrow$ The mesh structure of the Fe 50 in the $<1 \mathrm{ppb} \mathrm{NaOH}$

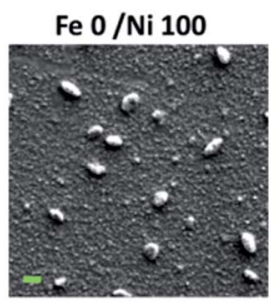

Fe $25 / \mathrm{Ni} 75$



Fe $75 / \mathrm{Ni} 25$

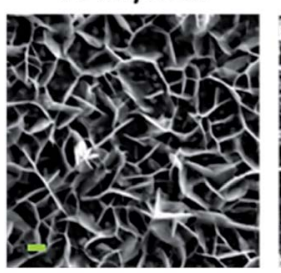

$\mathrm{Fe} 90 / \mathrm{Ni} 10$

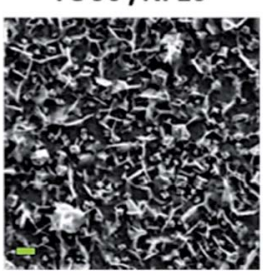

Fe $10 / \mathrm{Ni} 90$

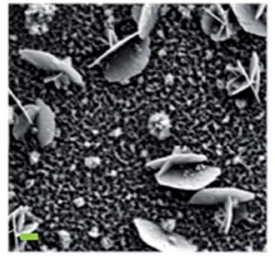

$\mathrm{Fe} 50 / \mathrm{Ni} 50$

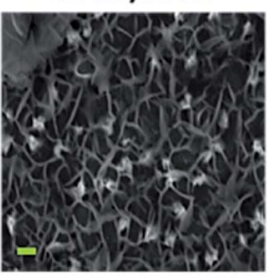

Fig. 1 SEM images for all as-deposited catalysts. Scale bar is $200 \mathrm{~nm}$. 


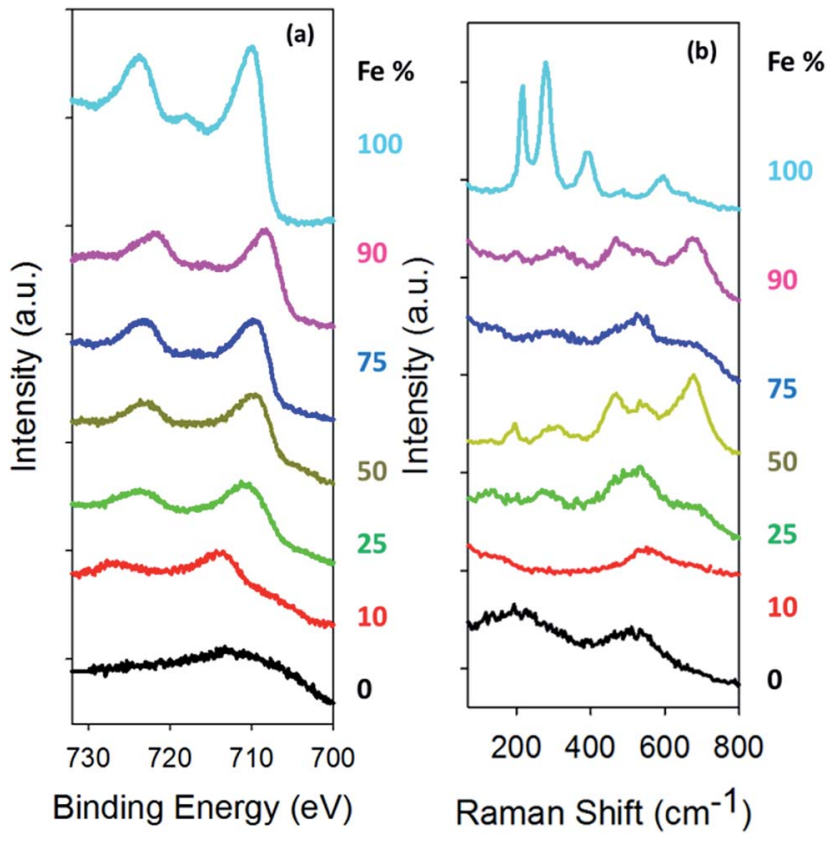

Fig. 2 (a) XPS analysis of the Fe $2 p$ core level peak and (b) Raman spectra of all pure and mixed oxides.

appears to become brittle following OER, while the mesh structure of the same material in a higher Fe concentration $\mathrm{NaOH}$ (5 and $102 \mathrm{ppb}$ ) appears to have kept its rigid mesh structure.

Following the electrodeposition of the films, XPS was utilized to determine the concentration of Fe on the surface, Fig. 2a and S5 and Table S3. $\dagger$

Analysis of the of $\mathrm{Ni} 2 \mathrm{p}_{3 / 2}$ and $\mathrm{Fe} 2 \mathrm{p}_{3 / 2}$ core level peaks reveals that for the as-deposited samples, the amount of Fe deviates only slightly by $1-6 \%$ from the initial precursors. For the precursor solutions of $10-75 \%$ the XPS indicates that the Fe is over-depositing on the electrode surface while the precursor solution of $90 \%$ the iron is under-depositing, compared to the quantity of $\mathrm{Fe}$ in the depositing solution. The $\mathrm{Ni} 2 \mathrm{p}_{3 / 2}$ core-level of the pure $\mathrm{Ni}$ as-deposited sample was fitted to a $\mathrm{Ni}^{2+}\left(\mathrm{Ni}(\mathrm{OH})_{2}\right)$ multiplet set, ${ }^{35}$ with only very minor contributions from $\mathrm{Ni}^{0}(\mathrm{Ni}$ metal) and no evidence of $\mathrm{NiOOH}$, Fig. S6a. $\dagger$ The Fe $2 \mathrm{p}_{3 / 2}$ peak of the as-deposited $\mathrm{Fe}$ pure catalyst was fitted with contributions correlating to $\mathrm{Fe}^{3+}\left(\mathrm{Fe}_{2} \mathrm{O}_{3}\right)$ and a minor contribution from $\mathrm{Fe}^{2+}\left(\mathrm{Fe}_{3} \mathrm{O}_{4}\right)$, Fig. S6b. $\dagger^{+36}$ The as-deposited Fe 50 sample, Fig. 6c, displays the fitting of the $\mathrm{Fe} 2 \mathrm{p}_{3 / 2}$ core level to a $\mathrm{NiFe}_{2} \mathrm{O}_{4}$ multiplet set with a minor contribution to $\mathrm{Fe}^{3+}\left(\mathrm{Fe}_{2} \mathrm{O}_{3}\right)$.

Raman spectroscopy was also performed on the pure $\mathrm{Ni}$ and Fe as deposited electrodes to confirm the presence of $\alpha-\mathrm{Ni}(\mathrm{OH})_{2}$ and $\mathrm{Fe}_{2} \mathrm{O}_{3}$ respectively, Fig. $2 \mathrm{~b}$ and $\mathrm{S} 7 . \dagger$ Subsequently, the mixed as-deposited electrodes were analysed with Raman spectroscopy to investigate the Raman active modes associated with the two pure materials in the mixed Ni/Fe oxide materials. This data is presented in Fig. 2b. Raman spectra of the Fe 0 material show a peak at $\sim 505 \mathrm{~cm}^{-1}$ which corresponds to $\mathrm{Ni}(\mathrm{OH})_{2}$. Previous studies have reported that the $\mathrm{Ni}(\mathrm{OH})_{2}$ species produces one Raman band in the region of 445-465 $\mathrm{cm}^{-1}$ attributed to a symmetric $\mathrm{Ni}-\mathrm{OH}$ stretching vibration or the $\mathrm{E}_{\mathrm{g}}(\mathrm{R})$ mode. ${ }^{37}$ However, a shift of up to $65 \mathrm{~cm}^{-1}$ can be observed from this region in disorder or doped $\mathrm{Ni}(\mathrm{OH})_{2} \cdot{ }^{23,38}$ This band indicates that a disordered $\mathrm{Ni}(\mathrm{OH})_{2}$ is present, which is further supported by the broadness of the peaks. ${ }^{39,40}$ As the deposition solution is made up of nickel sulphate, it is possible that sulphate ions have been incorporated into the $\mathrm{Ni}(\mathrm{OH})_{2}$ lattice during deposition causing the $\mathrm{Ni}-\mathrm{O}$ vibration of the $\mathrm{Ni}(\mathrm{OH})_{2}$ to blue shift. Another reason for the increase in wavenumbers could be due to the amorphous structure of these electrodeposited materials, which has been previously reported by Trotochaud et al. by GIXRD analysis. ${ }^{22,41}$ The broad peak at $\sim 230 \mathrm{~cm}^{-1}$ could be associated with impurities or from $\beta-\mathrm{Ni}(\mathrm{OH})_{2} \cdot{ }^{39}$ However, $\beta-\mathrm{NiOH}_{2}$ has a very sharp and clean Raman spectrum, therefore the disappearance of the peaks $\sim 230 \mathrm{~cm}^{-1}$ is more than likely due to the loss of contaminants in the films during cycling and not to do with $\beta-\mathrm{NiOH}_{2}$ present at all. ${ }^{39} \mathrm{NiOOH}$ was not detected in the as-deposited Fe 0 sample, which can also be confirmed by high resolution XPS of the Ni $2 \mathrm{p}$ core level, Fig. S6. $\dagger^{42}$ The peaks observed at 214, 279, 391, 487 and $594 \mathrm{~cm}^{-2}$ are characteristic of $\mathrm{Fe}_{2} \mathrm{O}_{3}$, Fig. S9. $\dagger^{\mathbf{4 3 , 4 4}}$ For the samples Fe 25, 50, 75 and 90, various peaks can be observed around 200-700 $\mathrm{cm}^{-1}$, which are attributed to spinel $\mathrm{NiFe}_{2} \mathrm{O}_{4}$. Raman peaks at 207 (weak), 355 (weak), 483, 574 and $703 \mathrm{~cm}^{-1}$ are indicative of the spinel $\mathrm{NiFe}_{2} \mathrm{O}_{4} \cdot{ }^{30,44}$ The Fe 50 sample exhibits all of these vibrations indicating the combination of the $\mathrm{Ni}$ and $\mathrm{Fe}$ creates a spinel $\mathrm{NiFe}_{2} \mathrm{O}_{3}$ new phase for this $\mathrm{Ni} / \mathrm{Fe}$ ratio.

Raman Spectroscopy was also utilised after OER activity for all catalyst in the three $\mathrm{NaOH}$ solutions with varying Fe impurity concentration ( $<1 \mathrm{ppb}, 5 \mathrm{ppb}$ and $102 \mathrm{ppb})$ to determine the difference in oxide structure from the as-deposited structure. Interestingly, for the Fe 0/Ni 100 sample, Fig. S10, $\uparrow$ it was found that the as-deposited $\mathrm{Ni}(\mathrm{OH})_{2}$ material did not change after OER, as evidenced by the presence of one Raman peak at 528-545 nm, depending on the electrolyte ${ }^{45}$ A new peak arose at the wavelength of $\sim 190 \mathrm{~cm}^{-1}$ for the Ni 100 in the $\mathrm{NaOH}$ with $102 \mathrm{ppb}$ Fe impurities. This could represent a $\mathrm{Fe}-\mathrm{O}$ vibration produced from the deposition of the Fe impurities from the $\mathrm{NaOH}$ at the higher potentials during OER. From Pourbaix diagrams, $\mathrm{Fe}_{2} \mathrm{O}_{3}$ can be produced at a $\mathrm{pH}$ of 14 at in the OER region. The presence of the band at $\sim 200 \mathrm{~cm}^{-1}$ could be brought by the $\mathrm{A}_{1 \mathrm{~g}}$ in plane $\mathrm{Fe}-\mathrm{O}$ vibration mode of $\mathrm{Fe}_{2} \mathrm{O}_{3}$ or by a Raman active mode in $\mathrm{Fe}_{3} \mathrm{O}_{4}{ }^{46,47}$ Finally, the thickness of the films was determined to be approximately $250 \mathrm{~nm}$ by profilometry.

\section{OER characteristics}

The catalytic activity of the electrochemically prepared oxide materials was evaluated via linear potential sweep voltammetry in various aqueous media with different amounts of Fe impurities at a sweep rate of $1 \mathrm{mV} \mathrm{dec}{ }^{-1}$. The pertinent LSV curves are presented in Fig. 3a-c, where the rising current indicates the region in which oxygen evolution is observed.

Interestingly, in all three electrolytes with various $\mathrm{Fe}$ concentration impurities, the mixed catalysts with Fe content of 25, 50, 75 and $10 \%$ exhibit lower overpotentials at $10 \mathrm{~mA} \mathrm{~cm}^{-2}$ than the pure Fe and pure Ni. However, the overpotential of 

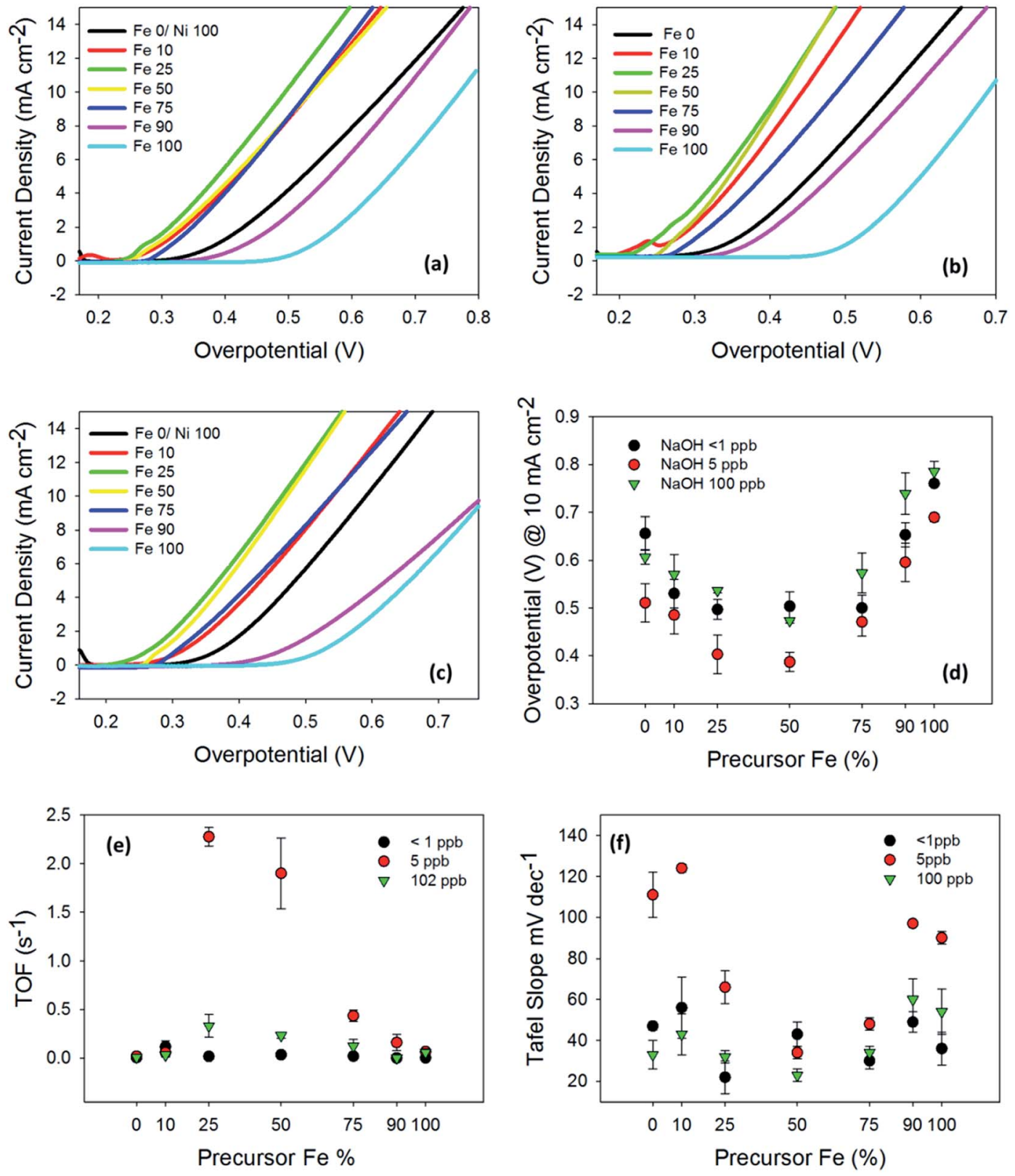

Fig. 3 (a) OER polarization curves of all pure and mixed Fe catalysts in the $\mathrm{NaOH}$ electrolyte containing Fe impurities of $<1$ ppb. (b) OER polarization curves of all pure and mixed Fe catalysts in the $\mathrm{NaOH}$ electrolyte containing Fe impurities of 5 ppb. (c) OER polarization curves of all pure and mixed Fe catalysts in the $\mathrm{NaOH}$ electrolyte containing Fe impurities of $102 \mathrm{ppb}$. (d) Summary of the overpotentials at $10 \mathrm{~mA}^{\mathrm{cm}}{ }^{-2}$ obtained by all catalysts. (e) Turnover Frequencies (TOF) numbers of all catalysts and (f) Tafel slope values of all catalysts.

each catalyst varies with Fe impurities in the different electrolytes. The incorporation of $\mathrm{Fe}$ into the Ni lattice is known to change the physical structure and conductivity of the compound enhancing the mixed oxides performance compared to the pure oxides through deposition/fabrication of the electrodes and by Fe impurities in the $\mathrm{KOH}$ base. ${ }^{11}$ In $\mathrm{KOH}$ with Fe impurities, the Ni oxide film performs as a better OER catalyst then the Fe and Fe 90 materials. In literature, the purification of the $\mathrm{KOH}$ base, i.e. the taking out of all the Fe impurities in the $\mathrm{KOH}$, leads to the pure Ni oxide exhibiting worse OER activity compared to the pure $\mathrm{Fe}$ and $\mathrm{Fe} 90$. Interesting, this decrease in performance of the pure nickel oxide compared to the pure Fe and Fe 90 materials is not observed in any of the $\mathrm{NaOH}$ solutions, including the purified $\mathrm{NaOH}$, Fig. 3a-c. The $\mathrm{NaOH}$ solution with lowest Fe impurity levels in this study contains less than $1 \mathrm{ppb}$ of Fe; however, this may be enough Fe in solution to substitute in for the octahedral Ni sites in the pure Ni oxide material and improve its OER performances.

The active site in the mixed $\mathrm{Ni} / \mathrm{Fe}$ oxide has been speculated to be the Fe. ${ }^{15,22}$ Therefore, the deposition of Fe impurities from the $\mathrm{NaOH}$ electrolyte will also play a critical role in the mixed $\mathrm{Ni} / \mathrm{Fe}$ activity as the percentages of the $\mathrm{Ni}$ and $\mathrm{Fe}$ in the catalyst 
will change. The Fe depositing onto the already fabricated $\mathrm{Ni} / \mathrm{Fe}$ oxide electrode may block the OER active sites reducing activity or the new deposited Fe may be more active than the material initial deposited on the electrode improving OER activity for various $\mathrm{Ni} / \mathrm{Fe}$ materials.

OER polarization curves for the pure and mixed $\mathrm{Ni} / \mathrm{Fe}$ oxide in the $\mathrm{NaOH}$ with Fe impurities of $<1$ are depicted in Fig. 3a. The catalyst with an initial precursor Fe percentage of 25 demonstrates the optimum overpotential at $10 \mathrm{~mA} \mathrm{~cm}{ }^{-2}$ for this electrolyte of $0.4967 \pm 0.0208 \mathrm{~V}$. Compared to the $\mathrm{NaOH}$ with $5 \mathrm{ppb} \mathrm{Fe}$ impurities, the best OER performing catalyst at this merit was the Fe 50, while $\mathrm{Fe} 25$ was a close performer to the Fe 50 with overpotentials at a current density of $10 \mathrm{~mA} \mathrm{~cm}{ }^{-2}$ of $0.387 \pm 0.02 \mathrm{~V}$ and $0.4029 \pm 0.04 \mathrm{~V}$, respectively. Similar to the $\mathrm{Fe}<1 \mathrm{NaOH}$ electrolyte, the $102 \mathrm{ppb} \mathrm{Fe} \mathrm{NaOH}$ also reveals the Fe 25 sample as the most OER active material with an overpotential value of $0.440 \pm 0.0265 \mathrm{~V}$.

The results from this study indicate that there is an optimum region of $\mathrm{Fe}$ impurities in the $\mathrm{NaOH}$ electrolyte for optimum OER performance. $102 \mathrm{ppb}$ of Fe may hinder the OER activity as the Fe impurities in the electrolyte may over-deposits blocking $\mathrm{Ni}-\mathrm{Fe}$ oxide active sites previously generated by the initial electrodeposition process from the metal salt. Additionally, the $\mathrm{NaOH}$ with $<1 \mathrm{ppb}$ of $\mathrm{Fe}$ impurities may not provide the extra Fe from the $\mathrm{NaOH}$ coupled with the initial $\mathrm{Ni} / \mathrm{Fe}$ oxide compound to enhance the OER activity. Whereas the $\mathrm{NaOH}$ with the $\mathrm{Fe}$ impurities of $5 \mathrm{ppb}$ exhibit improved OER performances with all catalysts compared to the $102 \mathrm{ppb}$ and $<1 \mathrm{ppb} \mathrm{NaOH}$.

Interesting, morphology can have a great effect on the OER activity of a material. ${ }^{48-50}$ Previous authors have suggested that the orientation of the film can increase/decrease the amount of nucleation sites and the frequency of the evolution of the $\mathrm{O}_{2}$ bubbles from the film freeing sites for more oxygen evolution. ${ }^{48}$ For example, the Fe 50 in $5 \mathrm{ppb} \mathrm{NaOH}$ may have a higher activity towards the OER due to a higher amount of sites oriented in an optimum way. Fig. S3 $\uparrow$ shows the SEM images Fe 50 material under all three electrolytes. The $5 \mathrm{ppb}$ (scale bar at $200 \mathrm{~nm}$ ) exhibits a more network defined mesh compared to the $1 \mathrm{ppb}$ and $102 \mathrm{ppb}$, which may facilitate in increase nucleation and evolution in this electrolyte. The slight change in morphology from the Fe 50 as-dep to $<1 \mathrm{ppb}$, with a morphology narrow/less dense mesh, to the $5 \mathrm{ppb}$ to the $102 \mathrm{ppb}$, with a mesh network more like the $5 \mathrm{ppb}$, could be due to the change in Fe content. According to the XPS analysis for the as-dep, $<1 \mathrm{ppb}, 5 \mathrm{ppb}$ and $102 \mathrm{ppb}$ the $\mathrm{Fe} \%$ is $51,50,44$ and 49 respectively.

(TOF) numbers for all catalysts in each of the three $\mathrm{NaOH}$ electrolytes were also determined. TOF provides a measure of the material's ability to produce oxygen per active site per unit time. One can readily rationalise the form of the TOF expression by considering the current density as a rate and relating the charge density to the quantity of electrochemically active material in the oxide film. ${ }^{51}$ Hence the TOF number is a rate per unit active material. The catalysts with the highest TOF numbers, in this study, are those in the $\mathrm{NaOH}$ with $5 \mathrm{ppb} F$ impurities, adding to the theory of a 'goldilocks' Fe impurity region for enhancing $\mathrm{Ni} / \mathrm{Fe}$ oxide materials towards the OER. For the $5 \mathrm{ppb} \mathrm{Fe} \mathrm{NaOH}$, the materials containing 25 and $50 \% \mathrm{Fe}$ show extremely positive TOF values of 2.3 and $1.8 \mathrm{~s}^{-1}$. These values are higher than previously reported TOF values for $\mathrm{Ni} / \mathrm{Fe}$ oxides in $\mathrm{KOH}$ electrolyte and $\mathrm{RuO}_{2}{ }^{12}$ The difference could be due to the amount of Fe present on the $\mathrm{Ni} / \mathrm{Fe}$ materials during OER, which enhances the OER performance. From the XPS, Table S3, $\uparrow$ there is a difference in the $\mathrm{Fe} \%$ before and after OER which could suggest that the ratio of $\mathrm{Fe}$ and $\mathrm{Ni}$ on the surface of the electrode is changing. Interestingly, for the Fe 25 and 50\% samples in the NaOH $5 \mathrm{ppb}$, the \% of Fe on the surface of the electrodes only differs by $5 \%$, Table S3. $\dagger$

From Pourbaix diagrams, in a $\mathrm{pH}$ of 14 and at high potential nickel oxide and iron oxides may oxidise to $\mathrm{NiO}_{4}{ }^{2-}$ and $\mathrm{FeO}_{4}{ }^{2-}$, respectively. However, no colour change in the solution is made during the OER regime indicating the dissolution of $\mathrm{Ni}$ and/or Fe into the aforementioned ionic species is more than likely not taking place. For example, the Ferrate ion $\left(\mathrm{FeO}_{4}{ }^{2-}\right)$ species is violet. The Raman spectroscopy, Fig. S10, $\dagger$ also confirms for the $\mathrm{Fe} 0$ catalyst that the higher $\mathrm{Ni}$ ionic species are not present during the OER regime as only one peak is present which can be attributed to $\mathrm{Ni}(\mathrm{OH})_{2}{ }^{23}$

Tafel slope values for the catalysts in the three $\mathrm{NaOH}$ solutions were also determined, Fig. $3 \mathrm{f}$. The Tafel slope is an extremely important parameter to consider when examining OER catalyst. The Tafel slope, defined as $b=2.303(R T / \alpha F)$, where $T$ is temperature, $\alpha$ is the symmetry factor and $R$ and $F$ are the gas and Faraday constants, is a measure of the sensitivity of the OER rate with respect to change in OER driving force (the applied potential). The lower the value of the Tafel slope the more efficient is the electrocatalyst. As shown in Fig. 3e, the Tafel slope decreases in a triangular manner from the pure $\mathrm{Ni}$ and pure $\mathrm{Fe}$ as the oxide composition reaches that of Fe 25-50 depending on the $\mathrm{NaOH}$ solution used. For all $\mathrm{NaOH}$ solutions there are 2 slight outliers the Fe 10 and Fe 90. The pure Ni and Fe materials in the $5 \mathrm{ppb} \mathrm{Fe} \mathrm{NaOH}$ exhibits are higher Tafel slopes suggesting a different OER mechanism is taken place for these materials than in the $<1 \mathrm{ppb}$ and $102 \mathrm{ppb} \mathrm{NaOH}$ solutions. The different mechanisms could be due to the amount of Fe available in the alkaline media. Additionally, the difference in the $5 \mathrm{ppb} \mathrm{NaOH}$ between the Tafel slope values for the pure $\mathrm{Ni}$ and Fe oxides and the Fe 50, the material with the lowest Tafel slope for this solution, is the greatest when comparing with the other $\mathrm{NaOH}$ solutions. As already previously mentioned in the literature, Tafel slopes can help elucidate a possible OER mechanism. ${ }^{52,53}$ Tafel slopes of 120,60 and $40 \mathrm{mV} \mathrm{dec}^{-1}$ correspond to a first electron transfer step, a chemical step and the second electron transfer step being rate determining in the consecutive OER reaction sequence, respectively. The Ni 100, Fe 90, Fe 10 and Fe 100 materials in the $5 \mathrm{ppb} \mathrm{NaOH}$ exhibit Tafel slopes in the range of $90-124 \mathrm{mV} \mathrm{dec}{ }^{-1}$ which would suggest a first electron transfer step for the rate determining step (RDS) for the OER. The Fe 10, Fe 25 and Fe 90 in the $\mathrm{NaOH}$ solutions of $<1 \mathrm{ppb}, 5 \mathrm{ppb}$ and $102 \mathrm{ppb}$ respectively have Tafel slope values between 56 and $66 \mathrm{mV} \mathrm{dec}^{-1}$ that indicate a chemical step as the RDS. All other materials, with the exclusion of Fe 75 and 25 in $<1 \mathrm{ppb}$, Fe 50 in $5 \mathrm{ppb}$ and $\mathrm{Fe}$ 75-25 in $102 \mathrm{ppb}$, indicate a RDS of a second electron transfer before the OER, as these materials display Tafel slopes of approximately $40 \mathrm{mV} \mathrm{dec}{ }^{-1}$. 




Fig. $4 \mathrm{Ni} 2 \mathrm{p}_{3 / 2}$ core level of the Fe 0 sample after the OER in the $\mathrm{NaOH}$ containing an Fe content of (a) 0 (As-Dep) (b) $<1 \mathrm{ppb}$ (c) $5 \mathrm{ppb}$ and (d) $102 \mathrm{ppb}$.

The Fe 75 and 25 in $<1$ ppb, Fe 50 in 5 ppb and Fe 75-25 in $100 \mathrm{ppb}$ materials all exhibit Tafel slope values of approximately $30 \mathrm{mV} \mathrm{dec}^{-1}$.

Interestingly, these materials all perform very well in respect to overpotentials at $10 \mathrm{~mA} \mathrm{~cm} \mathrm{~cm}^{-2}$ and TOF numbers. The lower tafel slope, exhibited by Fe 75 and 25 in $<1$ ppb, Fe 50 in 5 ppb and $\mathrm{Fe}$ 75-25 in $102 \mathrm{ppb}$, could be attributed to an optimum coverage of active sites by the mixed catalysts cause by the change in morphology, Fig. 1, to materials with a large mesh density with the same amount of material used to make the pure materials. This Tafel slope value of $30 \mathrm{mV} \mathrm{dec}^{-1}$ has been previously reported as the value for $\mathrm{Ni} / \mathrm{Fe}$ Layered Double Hydroxide ( $\mathrm{LDH}$ ) catalysts for the OER in $1 \mathrm{M}$ base. ${ }^{54}$ These results shows that using electrodeposition, which is cheap, easy and not time consuming, can fabricate mixed Ni/Fe oxides which produce similar Tafel slope values to $\mathrm{LDH}$ materials.

\section{High resolution XPS-OER species}

High resolution ex situ XPS was used to determine the surface species of the pure $\mathrm{Ni}$, pure $\mathrm{Fe}$ and the mixed $\mathrm{Fe} 50$ oxide catalysts after OER. One must note that XPS is a surface sensitive technique and only probes the top 2-10 nanometres of a sample. However, this 2-10 nanometre area is also the region of any electrode in contact with an electrolyte hence one of the most important regions, to understand, for OER activity. To detect the presence for other Ni or Fe species in the bulk of the films after OER, Raman was also utilised.

High resolution scans of the $\mathrm{Ni} 2 \mathrm{p}_{3 / 2}$ core level peak spectral region allowed contributions to be fitted to each sample, Fig. 4. The fitting of these high resolution peaks is extremely important as it allows the assigning of various species and was achieved using known parameters from a study by Grosvenor et al. ${ }^{35}$
The results show that $\mathrm{Ni}(\mathrm{OH})_{2}$ is the dominant species in the $<1 \mathrm{ppb}, 5 \mathrm{ppb}$ and $102 \mathrm{ppb}$ samples, and none of the fits yielded evidence for the presence of significant amounts of NiOOH. A small varying amount of Ni metal is present in all the samples, but with no apparent trend, Table S5. $\dagger$

From Fig. 4, it appears that the as-deposited Ni 100 sample and the three subsequent samples, which underwent OER in the various Fe containing $\mathrm{NaOH}$ electrolyte, appear to be in $\mathrm{a} \mathrm{Ni}^{2+}$ oxidation state. Hence, the oxidation state was not altered under OER potentials. This result varies from previously reported OER Ni active sites in $\mathrm{KOH}$ electrolytes containing no Fe content. $^{24,27}$ Friebel et al. used (DFT) calculations to determine that the $\mathrm{Ni}$ active site for OER is $\mathrm{NiOOH}$ or $\mathrm{Ni}^{4+}$. However, Landon et al. has shown using EXAFS that the initial Ni oxidation state in a Ni/Fe 90/10 material under the OER regime does not change in oxidation state. ${ }^{30}$ Perhaps due to the addition of the Fe from the electrolytes (containing Fe at a concentration of $<1,5$ and $102 \mathrm{ppb}$ ), the pure Ni sample, in this study, is behaving like a Ni/Fe mixed sample which has been investigated by Landon et al. Another study by Goerlin et al. in Fe-free electrolyte showed that with as little as $4 \% \mathrm{Fe}$ concentration in the $\mathrm{Ni} / \mathrm{Fe}$ catalyst, the $\mathrm{Ni}$ atoms are stabilized in a $2+$ oxidation state during OER. The Fe ions could be disrupting the nickel oxide from fully oxidising. It is heavily reported in the literature that pure Ni oxide behaves very differently in electrolytes with and without $\mathrm{Fe}^{22}$ Raman spectroscopy also confirm the presents of only $\mathrm{Ni}(\mathrm{OH})_{2}$ for all Ni 100 samples, Fig. S10. $\uparrow$ The XPS core level analysis of the Fe $2 \mathrm{p}_{3 / 2}$ core level and the EDX confirms the presence of Fe for the Ni 100 material after the OER in all electrolytes, Fig. S7 and S8. $\dagger$ Therefore the Ni 100 catalysts in this study could be behaving similar to the $\mathrm{Ni} / \mathrm{Fe}$ oxide catalysts produced by Goerlin et al. The XPS reveals, the Ni 100 catalysts in our study show a Fe concentration of 1-2\%, 13\%

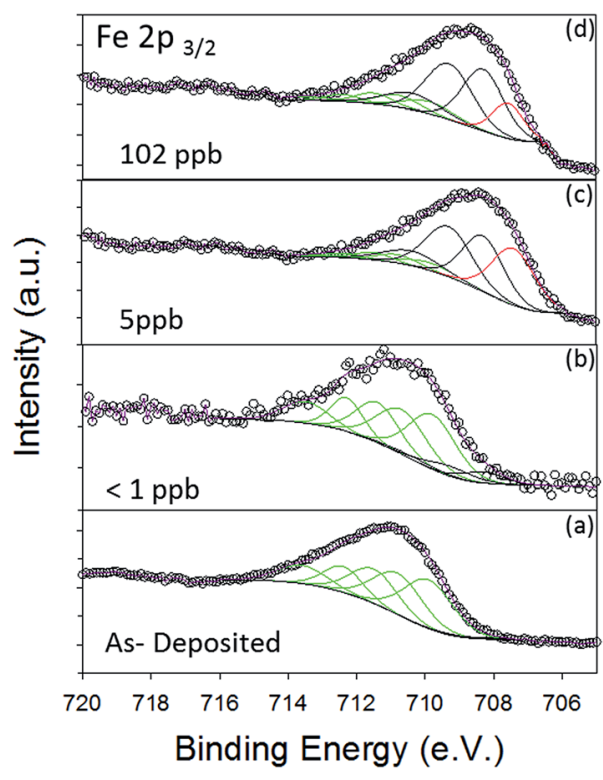

Fig. 5 Fe $2 p_{3 / 2}$ core level of the Fe 100 sample after the OER in the $\mathrm{NaOH}$ containing an Fe content of (a) 0 (As-Dep) (b) $<1 \mathrm{ppb}$ (c) $5 \mathrm{ppb}$ and (d) $102 \mathrm{ppb}$. 
and $13 \%$ after OER in $\mathrm{NaOH}$ with Fe concentrations of $1 \mathrm{ppb}$, $5 \mathrm{ppb}$ and $102 \mathrm{ppb}$, Table S2. $\dagger$

The high resolution $\mathrm{Fe} 2 \mathrm{p}_{3 / 2}$ core level peak for the as-deposited Fe 100 sample indicates that the Fe species is in an oxidation state of $3+$, Fig. 5a. After OER in the $<1 \mathrm{ppb} \mathrm{NaOH}$ electrolyte, the pure Fe 100 sample exhibits contributions from $\mathrm{Fe}^{3+}$ (major) and a slight amount of $\mathrm{Fe}^{2+}$, Fig. 5b. Interestingly, the same material in the $\mathrm{NaOH}$ electrolytes containing a higher amount of Fe (5 and $102 \mathrm{ppb}$ ) content display a higher amount of the $\mathrm{Fe}^{2+} / \mathrm{Fe}^{3+}$ oxidation state than $\mathrm{Fe}^{3+}$, Table S5. $\dagger$ This increase in the amount of $\mathrm{Fe}^{2+} / \mathrm{Fe}^{3+}$ compared to just the $\mathrm{Fe}^{3+}$ oxidation state could be due to the adsorption of the Fe species, which is in a lower oxidation state than the Fe on the electrode, from the electrolyte.

Subsequently, with increasing potential the Fe adsorbed onto the electrode surface from solution will also oxidise to higher oxidation states yielding $\mathrm{Fe}_{3} \mathrm{O}_{4}\left(\mathrm{Fe}^{2+} / \mathrm{Fe}^{3+}\right)$. Additionally, the reduction of the $\mathrm{Fe}^{3+}$ species to lower oxidation states by the incident x-rays during analysis is very unlikely and has never been reported. $\mathrm{Fe}_{2} \mathrm{O}_{3}$ is known to be a poor OER electrocatalyst and from Fig. 5, and Table S5, $\dagger$ it can be noted that the Fe 100 in the 5 ppb electrolyte contain the smallest amount of $\mathrm{Fe}_{2} \mathrm{O}_{3}$ on the surface of the electrode. ${ }^{30}$ This may be due to the increased OER performance of the $\mathrm{Fe} 100$ in the $5 \mathrm{ppb} \mathrm{NaOH}$ compared to the $<1 \mathrm{ppb}$ and $102 \mathrm{ppb} \mathrm{NaOH}$, Fig. 3d.

Ex situ XPS was also used to probe the oxidation states and $\mathrm{Fe} / \mathrm{Ni}$ species for the Fe 50 samples using the Fe 2p core peak region, Fig. $6 \mathrm{a}-\mathrm{d}$. The fitting of the $\mathrm{Fe}$ and $\mathrm{Ni} / \mathrm{Fe}$ peaks in the $\mathrm{Fe}$ $2 \mathrm{p}_{3 / 2}$ region were again done using parameters from previous work by Grosvenor et al. ${ }^{35,36}$ This enhancement in OER activity for the $5 \mathrm{ppb} \mathrm{NaOH}$ could be due to the change in the electronic state of the Fe oxide due to the insertion of more Fe oxide atoms into the $\mathrm{Ni} / \mathrm{Fe}$ lattice from solution, compared to the other

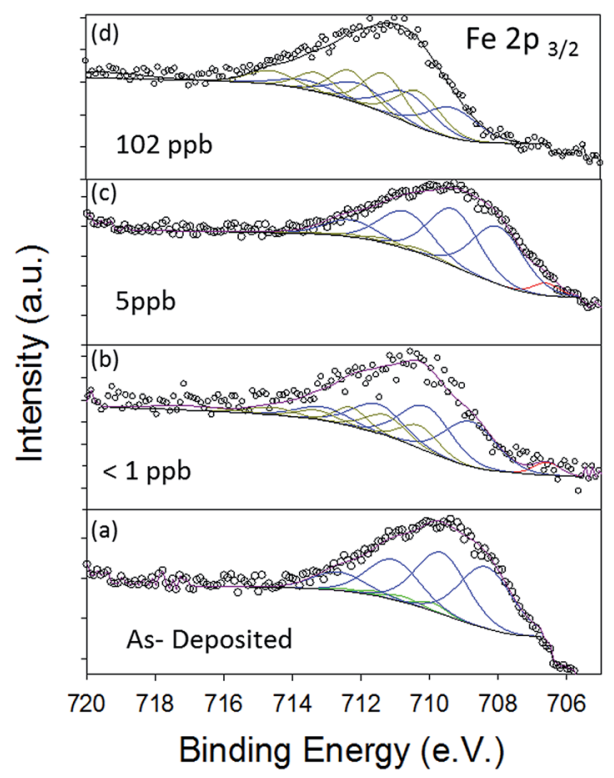

Fig. 6 Fe $2 p_{3 / 2}$ core level of the Fe 50 sample after the OER in the $\mathrm{NaOH}$ containing an Fe content of (a) 0 (As-Dep) (b) $<1 \mathrm{ppb}$ (c) $5 \mathrm{ppb}$ and (d) $102 \mathrm{ppb}$.
$\mathrm{NaOH}$ solutions. Interestingly, For the $\mathrm{Fe} 50$ samples the $\mathrm{NiFe}_{2} \mathrm{O}_{4}$ contributions, when comparing the $\mathrm{Fe} 2 \mathrm{p}_{3 / 2}$ peak, were $64.93 \%, 90.61 \%$ and 32.48 in the $\mathrm{NaOH}$ electrolyte solutions containing $<1 \mathrm{ppb}, 5 \mathrm{ppb}$ and $102 \mathrm{ppb}$ of Fe, respectively, Table S6. $\dagger$ The $\mathrm{NiFe}_{2} \mathrm{O}_{4}$ species is known to be a better OER catalyst when compared to its parent materials, nickel and iron. ${ }^{18,22,27,55}$ From Fig. 3, the OER activity of the Fe 50 catalyst in the $5 \mathrm{ppb}$ base is one of the optimum catalysts in this study. This could be due to the higher amount of $\mathrm{NiFe}_{2} \mathrm{O}_{4}$ in this catalyst/electrolyte combination compared with the other electrolytes, Fig. 6 and Table S6. $\uparrow$ The higher percentage of $\mathrm{NiFe}_{2} \mathrm{O}_{4}$ for the $\mathrm{Ni} / \mathrm{Fe}$ in the $5 \mathrm{ppb} \mathrm{NaOH}$ leads us to believe that the increased amount of the $\mathrm{NiFe}_{2} \mathrm{O}_{4}$ phase helps in the facilitation towards the OER and may explain the increased OER performances for all of the mixed $\mathrm{Ni} / \mathrm{Fe}$ oxide catalysts in the $5 \mathrm{ppb} \mathrm{Fe} \mathrm{NaOH}$.

The morphology of the material can play an important role in enhancing the OER performance. ${ }^{48}$ The morphology of the Fe 50 sample also exhibits a dense mesh morphology, while the parent material morphology shows a particle like morphology, Fig. S2-S4. $\uparrow$ This morphology, observed by the Fe 50 in 5 ppb $\mathrm{NaOH}$, may allow for quick nucleation and release/detachment of the $\mathrm{O}_{2}$ causing the re-generation of more active sites for more $\mathrm{O}_{2}$ product. The SEM images depict the surface area of the Fe 50 samples as bigger the than that of the pure Fe and Ni samples, therefore one may assume more electrochemical active sites on the Fe 50 sample which would explain the increased surface area. However, the charge density relates to the amount of electrochemically active redox species for a material, which is also assumed to be the amount of material which is active for the OER. ${ }^{51,52}$ In Fig. $3 \mathrm{~d}$ and S13, $\dagger$ the OER performance of the Fe 50 in 5 ppb shows that this material has the lowest overpotential at $10 \mathrm{~mA} \mathrm{~cm}{ }^{-2}$ and the second highest TOF values but displays a small charge density number indicating a smaller amount of electrochemical active sites compared to the Fe 0 film but a similar value when compared to the Fe 100 . This results would indicate that the change in morphology does not generate more active sites compared to the Fe 100 but may orientate these sites to an optimum position for the OER to maximise the generation and detachment of $\mathrm{O}_{2}$, similar to the 'cracked' $\mathrm{RuO}_{2}$ materials recently reported. ${ }^{48}$ This may also be true when comparing all of the 5 ppb samples in the three different electrolytes.

\section{Conclusion}

In this paper we have fabricated a series of mixed $\mathrm{Ni} / \mathrm{Fe}$ oxide materials on $\mathrm{Ti}$ substrates and examined their anodic water oxidation behaviour in aqueous alkaline solution as a function of oxide composition and the Fe impurity concentration in the alkaline solution, in which the OER behaviour was studied.

Some of the mixed oxides exhibited excellent activity for oxygen evolution with respect to TOF numbers. The catalysts containing a Fe precursor concentration of 25 and $50 \%$ in the $\mathrm{NaOH}$ with $5 \mathrm{ppb}$ Fe impurities exhibited TOF numbers of 2.3 and 1.7, respectively. These TOF values displayed by the aforementioned $\mathrm{Ni} / \mathrm{Fe}$ oxides are better than TOF values reported for $\mathrm{Ni} / \mathrm{Fe}$ oxide in $\mathrm{KOH}$ electrolyte and $\mathrm{RuO}_{2}$, which represents an important outcome in this field. Tafel slope values for a number 
of these Ni/Fe oxides are lower than Tafel slopes reported for $\mathrm{LDH} \mathrm{Ni/Fe} \mathrm{materials.} \mathrm{Subsequently,} \mathrm{all} \mathrm{of} \mathrm{the} \mathrm{mixed} \mathrm{materials}$ are far cheaper to produce than pure $\mathrm{RuO}_{2}$.

Interestingly, when comparing overpotential at a current density of $10 \mathrm{~mA} \mathrm{~cm}^{-2}$, all of the pure and mixed catalysts in the $\mathrm{NaOH}$ with $5 \mathrm{ppb}$ Fe impurities exhibit lower overpotentials than their counterparts in the $\mathrm{NaOH}$ electrolytes with $\mathrm{Fe}$ concentrations of $<1 \mathrm{ppb}$ and $102 \mathrm{ppb}$. This is also the trend for the TOF values, for most of the Ni/Fe materials in the $5 \mathrm{ppb} F$ $\mathrm{NaOH}$ electrolyte. Clearly, the OER activity of these materials in the $5 \mathrm{ppb} \mathrm{NaOH}$ material is enhanced compared to the $<1 \mathrm{ppb}$ and $102 \mathrm{ppb} \mathrm{NaOH}$.

This enhancement in OER activity could be due to the change in the electronic state of the Fe oxide due to the insertion of more $\mathrm{Fe}$ oxide atoms into the $\mathrm{Ni} / \mathrm{Fe}$ lattice from solution. The $\mathrm{NaOH}$ with a concentration Fe impurity of $5 \mathrm{ppb}$ could prove an optimum amount of Fe into the lattice which leads to improved OER activity compared to the same materials in electrolytes with lower $(<1 \mathrm{ppb})$ and higher $(102 \mathrm{ppb})$ amounts of Fe impurities. The XPS confirms that after OER different amounts of $\mathrm{Ni}$ and $\mathrm{Fe}$ are present on the surface of the pure Ni, pure Fe and mixed Fe 50 films.

\section{Conflict of interest}

The authors declare no competing financial interests.

\section{Funding sources}

This publication has emanated in part from research conducted with the financial support of Science Foundation Ireland (SFI) under Grant Number SFI/PI_10/IN.1/I2969 and SFI PI_10/IN.1/ I3030.

\section{Author contributions}

The manuscript was written through contributions of M. P. B., M. O. B., H. N., N. C. B. and M. E. G. L. All authors have given approval to the final version of the manuscript. M. P. B. and S. S. did the electrochemical analysis. M. P. B., M. O. B. and H. N. did the Raman analysis. M. P. B. and N. C. B. did the XPS. M. P. B. did the SEM and EDX. H. N. deposited Ti metal on the Si substrates.

\section{Acknowledgements}

We would like to thank the staff in the AML, CRANN for help with the SEM analysis. We would also like to thank the C. M. A for the ICP analysis. The authors would also like to thank Sinead Winters for the deposition of Ti metal on the Si substrates.

\section{References}

1 K. Zeng and D. Zhang, Prog. Energy Combust. Sci., 2010, 36, 307-326.

2 M. Gratzel, Nature, 2001, 414, 338-344.
3 M. P. Browne, H. Nolan, G. S. Duesberg, P. E. Colavita and M. E. G. Lyons, ACS Catal., 2016, 2408-2415.

4 Z. Li, W. Luo, M. Zhang, J. Feng and Z. Zou, Energy Environ. Sci., 2013, 6, 347-370.

5 M. E. G. Lyons, R. L. Doyle, D. Fernandez, I. J. Godwin, M. P. Browne and A. Rovetta, Electrochem. Commun., 2014, 45, 56-59.

6 M. Gong and H. Dai, Nano Res., 2015, 8, 23-39.

7 M.-R. Gao, X. Cao, Q. Gao, Y.-F. Xu, Y.-R. Zheng, J. Jiang and S.-H. Yu, ACS Nano, 2014, 8, 3970-3978.

8 M.-R. Gao, Y.-F. Xu, J. Jiang, Y.-R. Zheng and S.-H. Yu, J. Am. Chem. Soc., 2012, 134, 2930-2933.

9 M. Xing, L.-B. Kong, M.-C. Liu, L.-Y. Liu, L. Kang and Y.-C. Luo, J. Mater. Chem. A, 2014, 2, 18435-18443.

10 R. D. L. Smith, M. S. Prévot, R. D. Fagan, S. Trudel and C. P. Berlinguette, J. Am. Chem. Soc., 2013, 135, 11580-11586.

11 Z. Zhao, H. Wu, H. He, X. Xu and Y. Jin, Adv. Funct. Mater., 2014, 24, 4698-4705.

12 L. Trotochaud, J. K. Ranney, K. N. Williams and S. W. Boettcher, J. Am. Chem. Soc., 2012, 134, 17253-17261.

13 C. Bocca, A. Barbucci, M. Delucchi and G. Cerisola, Int. J. Hydrogen Energy, 1999, 24, 21-26.

14 M. Gao, W. Sheng, Z. Zhuang, Q. Fang, S. Gu, J. Jiang and Y. Yan, J. Am. Chem. Soc., 2014, 136, 7077-7084.

15 S. Klaus, M. W. Louie, L. Trotochaud and A. T. Bell, J. Phys. Chem. C, 2015, 119, 18303-18316.

16 J. R. Swierk, S. Klaus, L. Trotochaud, A. T. Bell and T. D. Tilley, J. Phys. Chem. C, 2015, 119, 19022-19029.

17 T. Takashima, K. Hashimoto and R. Nakamura, J. Am. Chem. Soc., 2012, 134, 1519-1527.

18 T. T. H. Hoang and A. A. Gewirth, ACS Catal., 2016, 6, 11591164.

19 M. K. Bates, Q. Jia, H. Doan, W. Liang and S. Mukerjee, ACS Catal., 2016, 6, 155-161.

20 M. Browne, R. J. Cullen, R. L. Doyle, P. E. Colavita and M. E. G. Lyons, ECS Trans., 2013, 53, 59-77.

21 L. Trotochaud and S. W. Boettcher, Scr. Mater., 2014, 74, 2532.

22 L. Trotochaud, S. L. Young, J. K. Ranney and S. W. Boettcher, J. Am. Chem. Soc., 2014, 136, 6744-6753.

23 M. W. Louie and A. T. Bell, J. Am. Chem. Soc., 2013, 135, 12329-12337.

24 S. Klaus, Y. Cai, M. W. Louie, L. Trotochaud and A. T. Bell, J. Phys. Chem. C, 2015, 119, 7243-7254.

25 Y. Gorlin and T. F. Jaramillo, J. Am. Chem. Soc., 2010, 132, 13612-13614.

26 D. A. Corrigan, J. Electrochem. Soc., 1987, 134, 377-384.

27 D. Friebel, M. W. Louie, M. Bajdich, K. E. Sanwald, Y. Cai, A. M. Wise, M. J. Cheng, D. Sokaras, T. C. Weng, R. Alonso-Mori, R. C. Davis, J. R. Bargar, J. K. Nørskov, A. Nilsson and A. T. Bell, J. Am. Chem. Soc., 2015, 137, 1305-1313.

28 R. L. Doyle and M. E. G. Lyons, Phys. Chem. Chem. Phys, 2013, 15, 5224-5237.

29 M. W. Louie and A. T. Bell, J. Am. Chem. Soc., 2013, 135, 12329-12337. 
30 J. Landon, E. Demeter, N. İnoğlu, C. Keturakis, I. E. Wachs, R. Vasić, A. I. Frenkel and J. R. Kitchin, ACS Catal., 2012, 2, 1793-1801.

31 M. Görlin, P. Chernev, J. Ferreira de Araújo, T. Reier, S. Dresp, B. Paul, R. Krähnert, H. Dau and P. Strasser, J. Am. Chem. Soc., 2016, 138, 5603-5614.

32 X. Zhang, H. Xu, X. Li, Y. Li, T. Yang and Y. Liang, ACS Catal., 2016, 6, 580-588.

33 J. A. Bau, E. J. Luber and J. M. Buriak, ACS Appl. Mater. Interfaces, 2015, 7, 19755-19763.

34 Q. Gao, C. Ranjan, Z. Pavlovic, R. Blume and R. Schlögl, ACS Catal., 2015, 5, 7265-7275.

35 A. P. Grosvenor, M. C. Biesinger, R. S. C. Smart and N. S. McIntyre, Surf. Sci., 2006, 600, 1771-1779.

36 A. P. Grosvenor, B. A. Kobe, M. C. Biesinger and N. S. McIntyre, Surf. Interface Anal., 2004, 36, 1564-1574.

37 Y. L. Lo and B. J. Hwang, Langmuir, 1998, 14, 944-950.

38 R. Kostecki and F. McLarnon, J. Electrochem. Soc., 1997, 144, 485-493.

39 D. S. Hall, D. J. Lockwood, C. Bock and B. R. MacDougall, Proc. R. Soc. London, Ser. A, 2015, 471, 1-65.

40 J. L. Bantignies, S. Deabate, A. Righi, S. Rols, P. Hermet, J. L. Sauvajol and F. Henn, J. Phys. Chem. C, 2008, 112, 2193-2201.

41 J. A. Carrasco, J. Romero, M. Varela, F. Hauke, G. Abellan, A. Hirsch and E. Coronado, Inorg. Chem. Front., 2016, 478487.

42 M. Zhou, H. Chai, D. Jia and W. Zhou, New J. Chem., 2014, 38, 2320-2326.

43 S.-H. Shim and T. S. Duffy, Am. Mineral., 2002, 87, 318-326.
44 P. Stelmachowski, A. Kopacz, P. Legutko, P. Indyka, M. Wojtasik, L. Ziemiański, G. Żak, Z. Sojka and A. Kotarba, Catal. Today, 2015, 257(1), 111-116.

45 R. Srnanek, I. Hotovy, V. Malcher, A. Vincze, D. McPhail and S. Littlewood, in Advanced Semiconductor Devices and Microsystems, 2000. ASDAM 2000. The Third International EuroConference on 2000, pp. 303-306.

46 Y. Jung, Y.-H. Son and J.-K. Lee, RSC Adv., 2012, 2, 58775884.

47 I. S. Molchan, G. E. Thompson, R. Lindsay, P. Skeldon, V. Likodimos, G. E. Romanos, P. Falaras, G. Adamova, B. Iliev and T. J. S. Schubert, RSC Adv., 2014, 4, 5300-5311.

48 A. R. Zeradjanin, A. A. Topalov, Q. Van Overmeere, S. Cherevko, X. Chen, E. Ventosa, W. Schuhmann and K. J. J. Mayrhofer, RSC Adv., 2014, 4, 9579-9587.

49 A. de Oliveira-Sousa, M. A. S. da Silva, S. A. S. Machado, L. A. Avaca and P. de Lima-Neto, Electrochim. Acta, 2000, 45, 4467-4473.

50 G. Lodi, C. de Asmundis, S. Ardizzone, E. Sivieri and S. Trasatti, Surf. Technol., 1981, 14, 335-343.

51 I. J. Godwin, R. L. Doyle and M. E. G. Lyons, J. Electrochem. Soc., 2014, 161, F906-F917.

52 R. L. Doyle, I. J. Godwin, M. P. Brandon and M. E. G. Lyons, Phys. Chem. Chem. Phys., 2013, 15, 13737-13783.

53 T. Shinagawa, A. T. Garcia-Esparza and K. Takanabe, Sci. Rep., 2015, 5, 13801.

54 M. Gong, Y. Li, H. Wang, Y. Liang, J. Z. Wu, J. Zhou, J. Wang, T. Regier, F. Wei and H. Dai, J. Am. Chem. Soc., 2013, 135, 8452-8455.

55 Y.-F. Li and A. Selloni, ACS Catal., 2014, 4, 1148-1153. 